\title{
El endeudamiento para el acceso a la vivienda: los modelos de justicia detrás de la protección constitucional al deudor*
}

Indebtedness for accesing housing: the models of justice behind the constitutional protection of the debtor

Yira López-Castro ${ }^{\mathrm{a}}$

Universidad del Rosario, Colombia

yira.lopez@urosario.edu.co

ORCID: https://orcid.org/0000-0001-7668-6780

David Hernández-Zambrano

Universidad del Rosario, Colombia

ORCID: https://orcid.org/0000-0002-3972-2612
DOI: https://doi.org/10.11144/Javeriana.vj69.eavm

Recibido: 06 Septiembre 2019

Aceptado: 20 Febrero 2020

Publicado: 21 Diciembre 2020

\section{Resumen:}

En Colombia, las políticas habitacionales han condicionado el acceso a la vivienda digna al endeudamiento de los ciudadanos. Así, introducida en la cotidianidad de la ciudadanía y materializada a través de relaciones de poder asimétricas, la deuda se inserta en las preocupaciones constitucionales como una reacción a las fallas de la distribución de la vivienda a través del modelo de mercado. En este contexto, este artículo de investigación presenta la construcción de la figura del deudor en las políticas públicas desde los años treinta, y reconstruye la forma en la que la jurisprudencia de la Corte Constitucional ha contribuido con la definición de dicho sujeto. Para realizar el análisis, el texto caracteriza los modelos abstractos de justicia que yacen tras las justificaciones de la protección del deudor y señala los problemas derivados de la adopción de dichas justificaciones.

Palabras clave: políticas habitacionales, financiación de vivienda, deudor, justicia, Corte Constitucional.

\section{Abstract:}

In Colombia, housing policies have made access to decent housing conditional on the citizen's acquisition of debt. Being part of people's everyday lives and instantiated by asymmetrical power relations, debt becomes a constitutional concern due to the failure of housing distribution using the market's logic. Within this context, this research article presents how public policies, since the 30s, built the characterization of the debtor and analyzes how the Constitutional Court has contributed to the definition of that subject. To advance the proposed analysis, this text characterizes the abstract models of justice that frame the justifications for protecting the debtor and shows the problems derived from the adoption of those justifications.

Keywords: housing policies, housing finance, debtor, justice, Constitutional Court.

\section{Introducción}

En Colombia, el modelo de mercado para el acceso a la vivienda es la consecuencia de un proceso en el que las políticas habitacionales transformaron el papel del Estado, que pasó de ser constructor, vendedor y financiador directo de vivienda, para limitarse a la función de subsidiar la demanda. Este modelo privilegia la propiedad como forma de vivienda que, siendo un bien costoso, convierte el crédito a largo plazo ofrecido por instituciones financieras en el elemento determinante para el acceso. A partir de dicho contexto, este artículo estudia la figura del deudor para, por un lado, identificar cómo las decisiones judiciales y las políticas públicas han moldeado este sujeto y, por otro lado, analizar los razonamientos constitucionales, enmarcados en un cambiante modelo de justicia, que determinan su protección.

En el modelo de mercado con subsidio a la demanda, los protagonistas de las transacciones inmobiliarias son los particulares, el escenario es el mercado y las reglas son las del derecho privado. No obstante, en Colombia, la jurisprudencia constitucional ha cumplido un rol determinante para la configuración de un

Notas de autor

\footnotetext{
${ }^{a}$ Autor de correspondencia. Correo electrónico: yira.lopez@urosario.edu.co
} 
sistema de financiación de vivienda que tiene como uno de sus principios, al menos formalmente, la protección de los deudores. El análisis acá presentado toma en cuenta tanto las decisiones y medidas adoptadas respecto de la adquisición de vivienda en tanto vinculada con la protección constitucional, como en lo referente a las diferentes concepciones de justicia a las que atienden los cambios en los mecanismos y formas de protección.

Este artículo, al preguntarse por las razones que justifican la protección de los ciudadanos en tanto deudores, contribuye a reconstruir el proceso de su definición institucional y a reconocer vacíos, inconsistencias y falencias en el diseño y justificación de su protección. En consecuencia, el artículo revela cómo, en Colombia, los individuos, más que agentes económicos libres o ciudadanos con derechos, son personas obligadas a entrar en la relación de crédito - asunto tradicionalmente regulado por el derecho privado- para materializar sus derechos humanos - típicamente enmarcados en el derecho constitucional.

Las reflexiones que se presentan en este escrito son el resultado del análisis de más de un centenar de sentencias ${ }^{1}$ y de documentos técnicos que contienen las decisiones estatales sobre el acceso a la vivienda. Metodológicamente, se realiza un análisis ideológico de la jurisprudencia constitucional, puesto que extrae las motivaciones axiológicas de las sentencias para captar su sentido "a partir de su correlación con una concepción política o con una cosmovisión más amplia"². Así, este artículo da cuenta de las visiones que sobre la justicia se encuentran detrás de las decisiones judiciales sobre las relaciones de crédito entre los bancos y sus deudores.

Tal análisis es presentado en tres partes que responden al problema planteado. La primera parte, para identificar el protagonismo del deudor en la jurisprudencia constitucional, comienza por situar a este sujeto en las políticas habitacionales que determinan el modo de acceder a una vivienda en Colombia. En la segunda parte, el texto evidencia cómo la jurisprudencia construyó el marco general de la protección del deudor motivada por la coyuntura de la crisis hipotecaria de 1999, atendiendo a criterios de justicia disonantes. Por último, el texto analiza la contracción de la protección constitucional, que obedece a un intento por refinar los criterios de protección del derecho a la vivienda.

\section{El endeudamiento como política pública}

La política pública en Colombia es que todos habremos de volvernos deudores. Nuestro acceso a una vivienda está mediado por la deuda. Resulta fundamental tener en cuenta que la vida privada de las personas se moldea, en gran medida, según los espacios previstos para ello por las decisiones políticas de su comunidad. La construcción de un plan de vida propio está mucho más determinada de lo que normalmente se interpreta en el ideario popular del liberalismo. Cuando se indaga con más cuidado sobre las implicaciones de la ciudadanía, encontramos que, como lo dice Rawls ${ }^{3}$, las personas no solo definen los criterios de justicia social que los han de regir como comunidad, sino que también, para la consecución de dicho propósito, han de concebir sus destinos como atados los unos a los de los otros. Así, quienes diseñan las políticas toman decisiones predicando, a nombre de la comunidad, los mecanismos y medios que se consideran idóneos y razonables para que los actores que la conforman adelanten sus planes de vida.

De esta manera, la política pública que versa sobre el acceso a la vivienda, además de proponer los lineamientos de un plan de gobierno en un tema específico, está marcando la pauta para el ejercicio y la vivencia de la ciudadanía en la vida cotidiana. La vivienda reúne varias caras del ámbito individual y social por ser, al mismo tiempo, un derecho, un bien, un medio de especulación y, por otra parte, un símbolo de progreso y realización social. Por estas razones, se hace necesario, reconstruir el surgimiento de la figura del deudor en las políticas públicas en Colombia, cuestión que presentamos a continuación.

Entre la década de los treinta y comienzos de los setenta, el Estado participaba directamente en los negocios sobre vivienda con instituciones públicas que construían, vendían a plazo y concedían crédito para la compra 
de bienes destinados al uso habitacional ${ }^{4}$. Además del diseño institucional, el rol activo del Estado se manifestó en la defensa de la regulación de las relaciones contractuales de arrendamiento ${ }^{5}$ de adquisición financiada ${ }^{6}$. Posteriormente, entre 1972 y el final de los noventa, los gobiernos concibieron la vivienda como un instrumento para la definición de políticas macroeconómicas y no como un objetivo de la política social. El plan de gobierno "Las Cuatro Estrategias" (1970-1974) con la intención de jalonar la economía definió como una de sus prioridades la "concentración de recursos en la industria edificadora para la construcción de vivienda urbana no subsidiada" ${ }^{7}$. Este plan acogió la propuesta de Lauchlin Currie, quien, en el documento denominado "Operación Colombia", recomendó que se diera "la mayor importancia" a las condiciones que hicieran posible que las empresas privadas construyeran y financiaran casas de bajo costo. Según esta propuesta, el país debía promover un desplazamiento de las personas que viven en el campo provocando una "migración acelerada" hacia las ciudades en las cuales debían construirse suficientes viviendas mediante el ofrecimiento de "alicientes poderosos al capital privado para suministrar unidades de alojamiento de bajo costo" 8 .

La tarea para alcanzar el camino trazado implicaba encontrar herramientas que hicieran compatibles los intereses de los diversos actores (deudores, ahorradores, constructoras y entidades financieras) para promover la celebración masiva de contratos de compraventa de vivienda y de crédito hipotecario. Ello significaba asegurarles a los ahorradores que se mantendría el poder adquisitivo de sus depósitos. Al mismo tiempo, era necesario incentivar a las entidades financieras privadas para que colocaran créditos a largo plazo que fueran atractivos para los deudores. Las herramientas decisivas para alcanzar esos múltiples propósitos fueron: i) las Corporaciones de Ahorro y Vivienda (CAV), ii) la Unidad de Poder Adquisitivo Constante (UPAC) y iii) el Fondo de Ahorro y Vivienda (FAVI).

Las CAV eran entidades financieras creadas con el privilegio exclusivo de remunerar los depósitos de ahorro a la vista mediante el ajuste periódico de su valor según la tasa de inflación y colocar esos recursos en créditos para vivienda en UPAC. Para que la corrección monetaria favoreciera tanto a los ahorradores como a los deudores, se estableció la UPAC que permitiría que los depósitos de los ahorradores no perderían valor y que los créditos a los constructores y compradores se sujetaran a una tasa máxima de interés fija durante todo el plazo del crédito en el que el interés era similar al índice de inflación. Se estableció que el valor en pesos de la UPAC se debía ajustar periódicamente según las fluctuaciones del poder adquisitivo de la moneda para proteger a los deudores de la inflación. Adicionalmente, se creó un fondo del Banco de la República denominado FAVI, que tenía por objetivo garantizar que cualquier disminución en los depósitos que pudiera tener efectos graves en la estabilidad de las CAV se solucionara con préstamos automáticos en UPAC a favor de estas. De esa forma, se remediaba una dificultad asociada a la correspondencia entre los depósitos de los ahorradores, los cuales son a la vista, y los créditos para vivienda, cuya característica principal es que son a largo plazo.

A finales de los años ochenta, Colombia le abrió camino al movimiento de globalización económica con ingredientes enmarcados por el Consenso de Washington (1989), el cual propuso fórmulas de política económica para los países en desarrollo que implicaban la reducción del Estado, la liberalización financiera y la desregulación. Tasas de interés reales determinadas por el mercado, apertura comercial, atracción de inversión extranjera, privatización de las empresas estatales, promoción de la competencia en escenarios desregulados y respeto de los derechos de propiedad, eran los ingredientes que implicaban la modificación de las políticas estatales en diversos sectores, entre ellos, el de vivienda, el cual fue "uno de los primeros en sufrir una reforma estructural que marca el inicio de una nueva fase regida por una política de mercado" .

De esa forma, el plan de desarrollo "La Revolución Pacífica" (1990-1994) consideró excesiva la intervención del Estado en la construcción y financiación de vivienda e impulsó el desmonte del esquema iniciado en la década de los treinta, que ya había sufrido un giro importante en el plan de gobierno 1970-1974. 
La última década del siglo XX se caracterizó por la implementación de un modelo de mercado con subsidios a la demanda en el que el Estado se ocuparía de crear diversos incentivos para alentar al sector privado a construir y financiar unidades habitacionales. Esta política habitacional se materializó con la expedición de un paquete de medidas legislativas relacionadas con (i) la estructura del sistema financiero, (ii) el ahorro para la adquisición de vivienda financiada y (iii) los subsidios para incentivar la demanda de crédito ${ }^{10 .}$

La política habitacional incluida en los planes de desarrollo 2002-2006 y 2006-2010 profundizó el modelo de mercado incentivando a los ciudadanos a ser propietarios mediante la siguiente fórmula: cuota inicial lograda por el ahorro privado (voluntario y obligatorio) + subsidios (para aquellos con menores recursos) + crédito (otorgado por entidades financieras). Posteriormente, los planes de desarrollo 2010-2014 y 2014-2018 incluyeron a la "locomotora de la vivienda" como uno de los sectores prioritarios de la agenda pública y continuaron con el esquema de cierre financiero en el que se combinan diversas clases de subsidios, crédito hipotecario o leasing habitacional y los recursos propios del comprador. Estos tres elementos varían según el nivel de ingresos de los hogares ${ }^{11}$. Adicionalmente, estos últimos planes de desarrollo, siguiendo los modelos chileno y brasilero, introdujeron la política de gratuidad mediante la creación del Subsidio Familiar de Vivienda en Especie para hogares que, por su situación de pobreza, pobreza extrema y vulnerabilidad priorizada $^{12}$, no tienen capacidad de ahorro ni acceso a crédito ${ }^{13}$. La política de vivienda para 2018-2022 continua con la focalización de incentivos según los ingresos de las familias y ha creado los programas Casa Digna, Vida Digna y Semillero de Propietarios ${ }^{14}$.

En resumen, las políticas habitacionales desde la década de los setenta, y con mayor fuerza en los últimos treinta años, convierten al deudor en uno de los protagonistas de las decisiones de la agenda política en materia de vivienda. Estas dinámicas de los planes de desarrollo en Colombia muestran concordancia con los procesos regionales que han mutado desde la confianza en el Estado proteccionista en los años cincuenta, pasando por una hibridación entre el control político de la economía y una relativa apertura al capital extranjero en los años setenta, hasta la apertura al mercado de los años ochenta y noventa que luego tratarán de ser conciliadas con los DD.HH. ${ }^{15}$.

Estas tendencias resultan de especial interés porque encarnan una mutación en la concepción de justicia y en la jerarquía entre valores relacionados con esta que se materializan en derechos subjetivos. Consecuentemente, la definición del deudor, de su rol, y de la forma que debe adoptar su tratamiento, expresan valores y concepciones de justicia diferentes, asunto que se abordará en las secciones siguientes.

\section{Durante la crisis: el deudor como sujeto de protección constitucional}

Esta parte analizará los principales argumentos empleados por la Corte Constitucional para considerar al deudor como sujeto de protección. La jurisprudencia ha indicado que los deudores merecen ser protegidos constitucionalmente porque son: víctimas de las decisiones estatales sobre el sistema de financiación de vivienda que precedió a la crisis hipotecaria, titulares del derecho a la vivienda y del derecho al debido proceso contractual.

\section{Los deudores como víctimas de la regulación: los reclamos de justicia correctiva}

Esta primera perspectiva asumida por la Corte, que atiende los reclamos de las partes afectadas por la crisis hipotecaria de 1999, asume que los deudores han sido dañados por la acción estatal y, por ende, deben ser reparados en concordancia con su condición de víctimas de un actor claramente identificable. Acá, como en las siguientes secciones, se hace patente la relevancia y prioridad que tiene la labor de definición respecto de la evaluación de la justicia. Dependiendo de la definición del deudor asumida por la Corte, los intereses--, 
los valores y la acción pertinente para la realización de la justicia serán diferentes y, por ende, la jerarquía de los principios aplicables al caso resultará también variable. Así, para asumir al deudor como víctima, la Corte parte de la consideración de los intereses patrimoniales, de los valores de la seguridad jurídica y la autonomía de los deudores, llegando así a concluir que la acción pertinente es la reparación directa. Analicemos entonces los hechos y decisiones que llevan a la Corte a adoptar esta primera visión de la justicia.

Los cambios regulatorios de final de siglo habían afectado a las Corporaciones de Ahorro y Vivienda (CAV). Con las nuevas condiciones de promoción de competencia entre las entidades financieras, las CAV lograrían su supervivencia solo si podían trasladar a los créditos la remuneración que estaban otorgando a los depósitos. Al ser inviable modificar unilateralmente las condiciones contractuales sobre la remuneración en los créditos, las CAV solicitaron con frecuencia cambios en el cálculo de la UPAC para que esta pudiera incluir la tasa de interés de los depósitos a término fijo (DTF), con lo cual si se estaba pagando más a los ahorradores por sus depósitos se recibiría más de los deudores mediante la corrección monetaria. Así, comenzaron una serie de modificaciones a la UPAC, con lo cual la corrección que inicialmente crecía conforme al IPC pasó a vincularse a las tasas de interés ${ }^{16}$.

Mientras tanto, el optimismo por el crecimiento económico y los incentivos para la construcción y compra de vivienda generaron el escenario propicio para el endeudamiento de los consumidores. Al mismo tiempo, se produjo un aumento sostenido de los precios de los inmuebles, los cuales crecieron 45\% entre 1993 y 1997 , mientras el IPC lo hizo en $22 \%{ }^{17}$. En la cima del crecimiento del crédito hipotecario, y a la par con la expansión de la especulación en el precio de los inmuebles, se generó un aumento en las tasas de interés del mercado ${ }^{18}$, que se reflejó inmediatamente en el valor de la UPAC ${ }^{19}$.

Los consumidores comenzaron a notar que las cuotas de sus créditos hipotecarios superaban su capacidad de pago. Mientras aumentaba el valor en pesos del crédito al ritmo del incremento de las tasas de interés del mercado, los ingresos de los deudores apenas se ajustaban con la inflación. La cartera vencida aumentó y el precio de las viviendas se desplomó ${ }^{20}$. El sistema de financiación de vivienda había entrado en crisis.

En diciembre de 1998 el gobierno declaró el estado de emergencia social y económica ${ }^{21}$. La Corte Constitucional $^{22}$, por su parte, declaró la constitucionalidad de las medidas de emergencia económica, pero únicamente en relación con los actores que, según la Corte, merecían ser protegidos: los deudores individuales del sistema de financiación UPAC; las organizaciones solidarias de ahorro y crédito y las instituciones financieras públicas. Así, según lo indicado por la Corte, las medidas excepcionales no podían incluir a las entidades financieras privadas del sector no cooperativo.

Aunque la crisis condujo al cierre de entidades financiadoras, a la quiebra de constructores y a la afectación de los deudores individuales que adquirieron vivienda, eran estos últimos quienes, según la Corte

“merecen mayor protección por las complicadas circunstancias que atraviesan, en especial a causa del desmesurado aumento en las tasas de interés y de la errónea y perjudicial estructura del sistema UPAC, cuyos exagerados costos y réditos ligados al DTF han conducido al fracaso económico de la mayoría de los deudores de las clases media y baja"23.

Las medidas de emergencia debían proteger a los deudores de crédito para adquisición de vivienda, pues ellos eran "víctimas de la crisis generada por el sistema UPAC, por las altas tasas de interés y por el momento económico" ${ }^{24}$. Por tal razón, los alivios y beneficios para enfrentar la crisis debían recaer sobre las condiciones contractuales individuales.

Un par de meses después de las sentencias de la Corte Constitucional sobre las medidas de emergencia económica, el Consejo de Estado declaró nula la Resolución 18 de 1995 de la Junta Directiva del Banco de la República que establecía la metodología para fijar el valor de la UPAC ${ }^{25}$. La norma fue declarada nula porque ataba el cálculo de la UPAC a la DTF y con ello desconocía el artículo 134 del Estatuto Orgánico del Sistema Financiero según el cual, el cálculo de la UPAC debía ajustarse periódicamente "de acuerdo con las fluctuaciones del poder adquisitivo de la moneda en el mercado interno". 
Según la sentencia del Consejo de Estado, la mencionada resolución tampoco era acorde con la Ley Orgánica del Banco de la República (Ley 31 de 1992), la cual establecía que la Junta Directiva podría fijar la metodología para determinar el valor de la UPAC, "procurando que ésta también refleje los movimientos de la tasa de interés de la economía" ${ }^{26}$. Para el Consejo de Estado, la expresión "procurando" utilizada por la norma implicaba que la Junta Directiva no podía adoptar como un único criterio prevalente para el cálculo de la UPAC las tasas de interés, pues ello desvirtuaba "la índole y objetivos económicos de la UPAC", la cual debía estar "naturalmente ligada al índice de precios al consumidor (IPC) y sólo en mínima proporción a otros indicadores económicos"27.

Una semana después de la decisión del Consejo de Estado, la expresión "procurando que ésta [la UPAC] también refleje los movimientos de la tasa de interés en la economía” recibió una herida fatal, esta vez, por parte de la Corte Constitucional, que la declaró inconstitucional en la sentencia C-383 de 1999. La Corte, a diferencia de lo que indicó el Consejo de Estado en la mencionada sentencia de anulación, consideró que tal expresión afectaba la autonomía de la Junta Directiva porque la obligaba a tener en cuenta el indicador DTF para establecer la metodología de cálculo de la UPAC.

El derrumbe definitivo del sistema de financiación de vivienda, el cual se encontraba agonizando luego de la sentencia C-383 de 1999, ocurrió en septiembre de 1999 con la sentencia C-700. Esta sentencia declaró la inconstitucionalidad de todas las normas del Estatuto Orgánico del Sistema Financiero que estructuraban el sistema de financiación UPAC ${ }^{28}$, al considerar que tales normas debieron ser expedidas mediante leyes marco y no por el gobierno mediante decretos con fuerza de ley.

La expedición de la Resolución 18 de 1995 dio origen a interesantes controversias judiciales originadas en demandas de reparación directa promovidas por deudores que consideraban ser víctimas de una falla del servicio ocasionada por el Banco de la República. La Corte Constitucional se ha pronunciado al respecto adoptando distintas posiciones.

Así, en la sentencia C-955 de 2000, al analizar la constitucionalidad de varias de las reglas sobre el sistema de financiación establecidas en la Ley 546 de 1999, la Corte indicó que las normas que establecen la obligación de reliquidar los créditos y el derecho a recibir los abonos de las cifras canceladas en exceso por los deudores eran la forma en la que "el Estado, a través de la Ley, se anticipó a reconocer su eventual responsabilidad, al menos parcial, en los motivos que llevaron al colapso, y asumió voluntariamente los costos inherentes al resarcimiento de los deudores perjudicados"29. Adicionalmente, indicó que, "sin perjuicio de la responsabilidad patrimonial del Estado", los deudores pueden acudir a los jueces si estiman haber sufrido daños por los pagos efectuados por conceptos que la Corte declaró inexequibles.

En la sentencia T-340 de 2011, la Corte negó una acción de tutela promovida por el Banco de la República en contra de una sentencia del Tribunal Administrativo de Cundinamarca que consideró que la Junta Directiva del Banco incurrió “en una falla en el servicio público de regulación” al expedir la Resolución 18 y que, de ello era prueba la sentencia de anulación de tal resolución. De conformidad con la sentencia del Tribunal, la aplicación de la resolución le produjo un detrimento patrimonial al deudor demandante, el cual era imputable al Banco, puesto que este había expedido un acto administrativo que causó el mayor valor en las cuotas del crédito pagadas por el deudor mientras estuvo vigente la Resolución.

Un par de años después, la posición de la Corte sobre tal controversia cambió y en sentencia de unificación SU-353 de 2013 consideró que no podía imputársele al Banco de la República responsabilidad por emitir un acto posteriormente anulado, pues la resolución se había expedido en cumplimiento de una orden jurídica vinculante ${ }^{30}$.

Las demandas de reparación directa contra el Banco de la República, y también algunas acciones populares interpuestas por deudores, provocaron el inicio de otro controvertido y largo litigio, está vez promovido por el Banco en contra de las aseguradoras con las que había suscrito una póliza global bancaria. Ante un Tribunal de Arbitramento, el Banco pidió que se condenara a las aseguradoras a indemnizar los riesgos derivados de sus 
acciones regulatorias. En especial, solicitaba que las aseguradoras atendieran las condenas judiciales dictadas por la expedición de la Resolución 18.

Así, la controversia giró en torno a la interpretación del contrato de seguro para identificar si los riesgos regulatorios que habían dado lugar a condenas de reparación contra el Banco de la República por falla del servicio se encontraban amparados por la póliza. El Tribunal de Arbitramento falló en contra del Banco de la República ${ }^{31}$ y el Consejo de Estado resolvió desfavorablemente el recurso de anulación interpuesto por el Banco contra dicho laudo ${ }^{32}$.

Posteriormente, la Corte Constitucional, en la polémica sentencia de unificación SU-556 de $2016^{33}$, revocó el laudo porque consideró que adolecía de defectos sustantivos y fácticos. En relación con los sustantivos, la sentencia consideró que el laudo interpretó irrazonablemente el inciso $1 .^{\circ}$ del artículo 1624 del Código Civil conforme al cual, si no hay otro remedio contra una ambigüedad en una cláusula, se escogerá el sentido que obre "a favor del deudor". Al aplicar esta regla de interpretación la Corte entendió que el deudor era la aseguradora y no el Banco, lo que lo llevó a considerar que el riesgo alegado no se encontraba cubierto por la póliza.

Entre los reproches que mediante recurso de nulidad fueron realizados a la sentencia que revocó el laudo, las aseguradoras resaltaron la incoherencia de la Corte en relación con la responsabilidad del Banco de la República por la expedición de la Resolución 18 de 1995, puesto que, mientras en la sentencia SU- 353 de 2013 había considerado, al cambiar el precedente establecido en la sentencia T-340 de 2011, que no podía imputársele responsabilidad por la expedición de tal resolución toda vez que la misma se dictó con arreglo a una previsión legal, en la sentencia SU-556 de 2016 concluyó que los riesgos regulatorios en los que pudo haber incurrido sí estaban cubierto por la póliza.

Quizás las sentencias que se refirieron a los deudores como "víctimas" crearon efectos no buscados, pues abrieron el camino a demandas de reparación directa por parte de los deudores. Así, la aproximación a los deudores como víctimas generó implicaciones en términos de la responsabilidad estatal, quizás impensadas por la Corte Constitucional. Esto dio lugar a interesantes debates que evidencian las dificultades sobre las medidas para atender a los actores afectados por la crisis y el peso que conlleva ubicar a un sujeto en una determinada categoría jurídica.

De esta manera, encontramos que esta primera respuesta constitucional parte de un modelo de justicia correctiva en la que la defensa de la justicia depende de la posibilidad de restituir a la parte afectada, de forma tal que vuelva a estar en condiciones similares a las que detentaba antes de ser dañada. Dadas las incorrectas medidas adoptadas por el Estado colombiano, a este le corresponde resarcir a las personas e instituciones cuyos legítimos intereses se vieron vulnerados como resultado de las acciones del primero. Así, la Corte reconoció que la regulación pública afecta a los privados a través de sus decisiones sobre la economía y las maneras adecuadas de acceder a los derechos de los ciudadanos. En este caso la Corte denuncia la causación de un daño, precisamente, por las medidas adoptadas en favor de la desregulación de la economía y su entrega a las dinámicas del mercado.

\section{Los deudores como titulares del derecho a la vivienda: una generalización apresurada en busca de la justicia distributiva}

Esta segunda perspectiva de la Corte, mediada por la necesidad de encontrar un fundamento constitucional permanente para la defensa de los intereses del deudor — dado que su definición como víctima solo cobija los casos en que puede identificarse un responsable inequívoco del daño-, se torna hacia un modelo de justicia distributiva, típico del igualitarismo liberal, en el que el centro del razonamiento no es ya el principio del daño, sino la responsabilidad pública de garantizar el goce de la ciudadanía por medio de la protección de sus derechos sociales y económicos. En concordancia, el interés tenido en cuenta es el del acceso a una 
vivienda digna, los valores son la equidad y la solidaridad de la comunidad política, y la medida adecuada es la intervención pública en los criterios de la justicia contractual para el caso del crédito hipotecario.

Así, el vínculo entre el derecho a la vivienda y la regulación de los contratos fue el sustento para la definición constitucional de reglas que establecen los derechos de los deudores y las correlativas obligaciones en cabeza de las entidades financieras, en el marco del contrato de mutuo. La necesidad de un régimen especial de financiación de vivienda fundado en la protección del derecho a la vivienda fue desarrollado en las sentencias C-252 de 1998, C-700 de 1999 y C-747 de 1999, en las cuales la Corte Constitucional creó reglas para los créditos a partir del derecho a la vivienda.

En la sentencia C-252 de 1998 la Corte analizó la regla según la cual el acreedor no puede ser obligado a recibir antes del vencimiento del plazo. En tal sentencia, la Corte declaró la constitucionalidad condicionada de los artículos 2229 del Código Civil y 694 del Código de Comercio, al considerar que esa regla general sobre el pago, que se encuentra en el contrato de mutuo (en el caso del artículo 2229 del Código Civil) y en el régimen de los títulos valores (artículo 694 del Código de Comercio), no puede ser aplicada a los deudores de crédito hipotecario porque estos contratos deben someterse a "una normatividad propia para los créditos de vivienda a largo plazo que otorgan las entidades, que impide, en principio, la aplicación automática de las normas civiles y comerciales que regulan la misma actividad" 34 .

De otra parte, la sentencia C-700 de 1999 que declaró la inconstitucionalidad de las normas que estructuraban el sistema de financiación de vivienda ${ }^{35}$ por no haber sido expedidas por el congreso, estableció que la ley marco que se expidiera para sustituir el régimen inconstitucional debía entender que la regulación del crédito para vivienda difiere de otras clases de actividades financieras, pues se ubica en el ámbito del derecho a la vivienda consagrado en el artículo 51 de la Constitución y, por lo tanto, "debe tener por objeto especial y directo el que dicha norma constitucional prevé, es decir, la fijación de las condiciones necesarias para hacer efectivo el derecho que todos los colombianos tienen a una vivienda" ${ }^{36}$.

En esta sentencia, la Corte Constitucional insistió en que la financiación de vivienda merecía una regulación especial acorde con el derecho que tienen todas las personas a un lugar decente para vivir. Así, según la sentencia, como no se trata de una actividad financiera cualquiera, las condiciones de los contratos de financiación no pueden simplemente someterse al régimen general en materia de contratos de mutuo.

Un mes después de este pronunciamiento, nuevamente la Corte en la sentencia C-747 de 1999 consideró que, aunque la capitalización de intereses en créditos a mediano o largo plazo es, en general, constitucional, no lo es cuando se trata de créditos para la adquisición de vivienda porque en esta clase de contratos "es evidente" que la capitalización viola el artículo 51 de la Constitución. Lo anterior porque la adquisición y la conservación de la vivienda implica la existencia de medidas que faciliten el pago a largo plazo en condiciones adecuadas.

En esta oportunidad, la demanda se había dirigido contra las reglas de capitalización de intereses del Estatuto Orgánico del Sistema Financiero ${ }^{37}$. En la misma dirección que las sentencias emitidas los meses anteriores, la Corte declaró la inconstitucionalidad de las reglas que se refieren a la capitalización de intereses "únicamente en cuanto a los créditos para la financiación de vivienda a largo plazo" ${ }^{38}$.

Ahora el turno era para el gobierno y el congreso. Era necesario pensar una regulación para los créditos de vivienda que atendiera los parámetros establecidos por la jurisprudencia constitucional que buscaban que el crédito de vivienda fuera sometido a unas condiciones especiales acordes con el derecho a adquirir y conservar un lugar habitable. Un par de semanas después de la expedición de la sentencia C-700 de 1999, el gobierno presentó el proyecto de ley que se convertiría en la Ley 546 de 1999, la cual es, hasta hoy, la ley marco para el sistema especializado de financiación de vivienda. La ley mantuvo la relación entre vivienda y propiedad individual a la que se accede mediante el crédito hipotecario, estableció un régimen general de financiación y uno especial para vivienda de interés social y reguló detalladamente las condiciones de los créditos de vivienda individual a largo plazo. 
Es importante resaltar que la sentencia C-700 de 1999 declaró inconstitucional el sistema de financiación UPAC, el cual no solamente se aplicaba a créditos para compra de vivienda, sino también a créditos para la compra de cualquier inmueble como oficinas, locales, bodegas, demás inmuebles comerciales y también a los créditos a los constructores. De esa forma, las normas declaradas inconstitucionales no establecían un tratamiento normativo diferente a los créditos al distinguir entre la clase de inmueble o el tipo de deudor. Sin embargo, la Ley 546, expedida para estructurar el sistema declarado inconstitucional, reguló únicamente el "sistema especializado para financiación de vivienda". En todo caso, a pesar de mencionar, dentro de las finalidades de la regulación, la protección al derecho a la vivienda digna, la Ley 546 no distingue, para efectos de las condiciones contractuales especiales, entre los deudores que acceden al crédito para comprar vivienda con el objetivo de vivir en ella de aquellos que compran segundas viviendas con finalidades de especulación. En este último caso, la vivienda adquirida mediante el crédito hipotecario se utiliza como un bien de inversión lo que implica que no está ligada intrínsecamente al derecho a la vivienda de los deudores.

En conclusión, las sentencias de constitucionalidad que configuraron el sistema de financiación de vivienda asumieron apresuradamente que todos los deudores son titulares del derecho a la vivienda, asunto que solo puede ser verificado en cada caso para conocer si la vivienda se utilizará para el uso personal o familiar o para desarrollar operaciones en el mercado habitacional. Con ello, el problema de esta segunda solución es que, persiguiendo la protección de los derechos sociales de los ciudadanos, la Corte termina por cobijar, bajo el derecho a la vivienda, los intereses económicos de prácticamente todos los compradores en el mercado inmobiliario. En otras palabras, se hace una generalización apresurada que identifica la vivienda con la propiedad privada y a los deudores con la titularidad de derechos habitacionales.

\section{Los deudores como contratantes: la reivindicación de la justicia procedimental}

En esta tercera perspectiva de la Corte, dada la coyuntura del ajuste de los contratos inmobiliarios derivada de la protección a los deudores como titulares del derecho a la vivienda, el centro de preocupación no es ya la reivindicación de un ideal de justicia social, sino el empeño por hacer que su implementación fuese ordenada y efectiva. De esta manera, la definición del deudor se relaciona con el derecho fundamental al debido proceso (Art. 29 de la Constitución, más fácilmente justiciable que el derecho social a la vivienda ${ }^{39}$, al priorizar su interés en tener expectativas estables en sus relaciones contractuales, y defender los valores de la igualdad formal, de la transparencia y el cumplimiento de las promesas. Así, siguiendo un modelo de justicia procedimental, la medida pertinente debe ser el aseguramiento del cumplimiento de los procedimientos contractuales tal como son voluntariamente aceptados por las partes.

Durante la ejecución de los contratos, las partes se relacionan mediante una serie de actuaciones y toma de decisiones que pueden afectar sus intereses e incluso sus derechos fundamentales. Siguiendo tal consideración, la Corte Constitucional ha sostenido que a la relación contractual entre una entidad financiera y un deudor hipotecario le son aplicables los principios que desarrollan el derecho fundamental al debido proceso.

De conformidad con la Ley 546 de 1999 y las sentencias de constitucionalidad sobre el sistema de financiación, las condiciones contractuales de los créditos debían ser modificadas para suprimir la capitalización de intereses, fijar una tasa de interés durante todo el plazo, permitir el pago anticipado total o parcial de la deuda sin penalización alguna y hacer los abonos que correspondieran a la diferencia entre el saldo en pesos de las obligaciones hasta el 31 de diciembre de 1999 y el saldo de la obligación reliquidado en la unidad UVR ${ }^{40}$.

Ajustar cada uno de los contratos celebrados no era un asunto en lo absoluto sencillo. En la práctica, se presentaron innumerables problemas para determinar el valor en concreto de los saldos, plazos, intereses y para informar adecuadamente a los consumidores al respecto. Luego de que las entidades financieras realizaron modificaciones a los sistemas de amortización que se aplicaban a los créditos de vivienda, se generó 
una avalancha de tutelas por parte de aquellos deudores que habían recibido comunicaciones contradictorias respecto a los saldos de los créditos ${ }^{41}$ o que no estaban de acuerdo con las reliquidaciones realizadas por los bancos $^{42}$.

Las numerosísimas sentencias sobre las modificaciones a las condiciones de los créditos han sido uniformes al considerar que las entidades financieras deben informar adecuadamente a los deudores para que estos puedan participar en la elección del sistema de amortización y que, en aquellos casos en los que las entidades expidieron paz y salvos o comunicaciones con un determinado saldo resulta aplicable la teoría de los actos propios y por tanto, configura una violación al debido proceso la conducta de los bancos de establecer que los saldos son superiores a los inicialmente comunicados ${ }^{43}$.

Así, en estas sentencias, el derecho cuya violación se analiza es el del debido proceso contractual y no el derecho a la vivienda, el cual no es fácilmente justiciable mediante la acción de tutela por estar ubicado en la Constitución como un derecho social. Es importante advertir que, en estas sentencias de tutela relacionadas con las consecuencias de la crisis hipotecaria en las relaciones contractuales particulares, al igual que ocurrió en las de constitucionalidad analizadas atrás, la Corte protege a todos los deudores, sin importar si el deudor afectado por la modificación vive o no en el inmueble o si el inmueble sobre el que gira la controversia contractual es el único inmueble del accionante o si el accionante se encuentra en un estado de indefensión especial diferente al que genera la asimetría en una relación de consumo de crédito.

Atendiendo la idea igualitarista de la necesidad de garantizar las condiciones económicas y sociales mínimas para la que los ciudadanos tengan la oportunidad de éxito en la sociedad civil, la Corte intentó encasillar al deudor, en los tiempos de la crisis, de tres formas que implican razonamientos de justicia diferentes y que muestran la dificultad de brindar medidas coherentes y a la vez efectivas de protección. Sin embargo, sus intentos resultaron insuficientes para entender y proteger adecuadamente al deudor fuera de los tiempos de crisis, por lo que, pasado el tiempo, hubo lugar a cambios jurisprudenciales que examinaremos a continuación.

\section{De la protección generalizada a la individualización de los deudores: entre la justicia formal y la justicia material}

Los efectos de la crisis le dieron la bienvenida al nuevo siglo. Los desembolsos de créditos para vivienda disminuyeron notablemente y el sector financiero y el de construcción redujeron su tamaño ${ }^{44}$. Para algunos, las decisiones de la Corte Constitucional que protegieron de manera general a los deudores habían sido la causa del marchitamiento del crédito para vivienda porque los habían convertido en negocios riesgosos para las entidades financieras. Así, consideraron nefastas las "interferencias jurisprudenciales" en los contratos de crédito, en tanto establecieron una protección "a ultranza de los deudores en dificultades financieras o insolvencia, en desmedro de los intereses de los acreedores" ${ }^{45}$, incentivando a que los ciudadanos incumplan sus promesas con la expectativa de contar con la posibilidad de que una decisión judicial modifique los términos contractuales.

La misma Corte Constitucional, a medida que se alejan los tiempos de crisis, ha reducido la protección generalizada que recibieron los deudores. Un primer giro para reducir el alcance de la protección a los individuos por el solo hecho de ser deudores ocurrió en la sentencia C-936 de 2003. Esta sentencia declaró constitucional la norma que permitió que los bancos realizaran operaciones de leasing habitacional. De conformidad con la norma, el Gobierno, al reglamentar la operación de leasing habitacional, debe adoptar medidas que garanticen la protección de los usuarios o locatarios ${ }^{46}$. En la demanda de inconstitucionalidad, el demandante señalaba que la norma permitía que las operaciones de leasing habitacional quedaran sometidas a la "lógica del mercado" ${ }^{47}$, afectando con ello el derecho a la vivienda. 
La sentencia C-936 de 2003 hizo importantes precisiones sobre el régimen que gobierna el leasing habitacional. Así, distinguió entre el deudor familiar y el deudor mercantil para efectos de establecer reglas contractuales adecuadas a los intereses que cada uno de estos deudores pretende alcanzar mediante la celebración de un leasing. De esa forma, el leasing celebrado por un deudor que destina el inmueble para vivir allí (leasing habitacional familiar) debe someterse al marco regulatorio establecido para los créditos hipotecarios, con lo cual a este contrato le son aplicables las reglas de protección establecidas en las sentencias C-383, C-700, C-747 de 1999 y C-955 de 2000 y en la Ley 546 de 1999. Por el contrario, el contrato de leasing con un deudor mercantil (leasing habitacional no familiar), es decir, aquel que celebra el contrato con el objetivo de explotar el inmueble económicamente, puede sujetarse a las condiciones de libre mercado.

De esa forma, esta sentencia consideró que solo los deudores que son titulares del derecho a la vivienda merecen ser protegidos constitucionalmente. Por el contrario, los deudores que

“están en capacidad de asegurar, por vías mercantiles ordinarias, la satisfacción de su derecho a la vivienda, sea mediante su adquisición, el arrendamiento u otras formas comunes en el tráfico comercial, no pueden exigir, como derecho constitucional, que sean inmunizados de manera absoluta frente las contingencias propias del mercado" 48

Así, un par de años después de la coyuntura de la crisis hipotecaria, la Corte se inclinó por la libertad contractual al considerar que algunos deudores tienen la capacidad de afrontar las consecuencias de que las condiciones contractuales se establezcan por el mercado. Bajo esta perspectiva, así como el legislador debía intervenir en las condiciones contractuales con el objetivo de proteger el derecho a la vivienda de los deudores, tendría también la posibilidad de establecer algunas modalidades en las que opere con mayor intensidad el mercado.

Además de lo que ocurre en materia de leasing habitacional, la jurisprudencia que resuelve acciones de tutela también ha restringido la protección a los deudores para verificar si el accionante es titular del derecho a la vivienda y si además se encuentra en una situación de indefensión. Esta posición se ha adoptado en las sentencias de tutela que analizan hechos que no están relacionados con la crisis hipotecaria. Así, estas sentencias ${ }^{49}$, que resuelven casos en los que los accionantes consideran vulnerados sus derechos fundamentales por una acción u omisión de una entidad financiera en relación con un contrato de crédito para vivienda, han considerado que la condición de deudor no es suficiente para lograr la protección del derecho a la vivienda y han seguido la argumentación que puede resumirse de la siguiente manera.

En primer lugar, la Corte reitera que las actividades que desarrollan las entidades financieras al celebrar contratos de financiación de vivienda se enmarcan en el concepto de servicio público ${ }^{50}$ y, por lo tanto, la intervención del Estado resulta fundamental para el desarrollo de esta actividad indispensable para la vida económica y social del país. Luego de ello, las sentencias señalan que la relación contractual con los consumidores es asimétrica porque estas entidades ostentan una posición dominante frente a los deudores. Seguidamente, señalan que el juez constitucional debe verificar la existencia de un "estado de debilidad manifiesta" atendiendo las circunstancias propias del accionante ${ }^{51}$.

Tal verificación de la particular indefensión del deudor supone que dentro de la categoría "deudores" hay una población que, por estar en una situación especial debido a que se encuentran enfermos, son ancianos, víctimas del conflicto, desempleados, personas cabeza de hogar, en situación de pobreza o de discapacidad, merecen protección constitucional mediante la tutela. En estos casos, la Corte ha indicado que, en virtud del deber de solidaridad ${ }^{52}$, surgen para las entidades financieras obligaciones concretas de protección de la vivienda ${ }^{53}$ y ha ordenado la celebración de contratos de crédito o la renegociación de las condiciones iniciales ${ }^{54}$

Como puede evidenciarse en esta tercera sección, la Corte, dada la relevancia de la figura del deudor derivada de la posición asignada a este por la política pública, redefine los límites de la distinción entre lo público, entendido como el espacio de intervención estatal, y lo privado, definido como el espacio de la libertad de transacción y asociación entre particulares, para justificar sus acciones y abstenciones respecto 
de la adjudicación del derecho a la protección constitucional. Por un lado, justifica su intromisión en la libertad contractual a través de, por ejemplo, la protección especial al locatario primario, arguyendo que el modelo de acceso a la vivienda implementado por la política pública hace del deudor un sujeto cuyos derechos constitucionales se ponen en juego al entrar en las relaciones de crédito hipotecario o leasing habitacional. Por otro lado, especifica la distinción para justificar su abstinencia de proteger por medios constitucionales al locatario mercantil e incluso al primario en casos en que no esté en especial condición de vulnerabilidad, para evitar el oportunismo y procurar así la eficiencia y eficacia de la protección otorgada.

Sin embargo, este foco en la justificación de la acción e inacción del sector público, que en gran medida puede entenderse como una forma de amoldarse y legitimarse frente a la tendencia de la política pública y frente a los reclamos de los actores del mercado de propender por la desregulación de las transacciones económicas, se abstiene, o se olvida, de dar garantías positivas respecto del cumplimiento de las protecciones otorgadas.

De esta manera, aunque bajo decisiones loables, el sistema de protección del derecho a la vivienda sigue permitiendo relaciones de dominación ${ }^{55}$ en las que la igualdad predicada de las actividades en el ámbito privado es sólo aparente dado que la acción definitiva para el otorgamiento de protección se confía a una acción altruista. El problema de que la Corte abra la posibilidad para que el legislador incluya la opción de leasing mercantil en el menú de opciones de acceso a unidades habitacionales no es dicha inclusión, sino que, al no asegurar la existencia, en el mercado, de contratos protegidos (por ejemplo a través de la imposición de cuotas porcentuales de recursos asignados a contratos de leasing habitacional familiar), hizo que la opción mercantil, inicialmente pensada solo como permisible pueda convertirse, a través de la decisión de los bancos, en la única opción disponible.

El punto problemático que queremos enfatizar es que mediante las inclusiones y exclusiones - en términos de protección, de definición, y de obligaciones y deberes - generadas por la política pública, la legislación y las sentencias de la Corte Constitucional, se configura una estructura social que termina por dejar la efectiva protección del derecho a la vivienda, especialmente para las poblaciones vulnerables, en manos del uso arbitrario del poder de decisión de los bancos, quienes determinan si una persona tiene la capacidad para comprometer su futuro a largo plazo con la promesa de pagar. Con ello se condiciona el cumplimiento de un derecho constitucional a la realización de un acto, basado en la solidaridad o el altruismo, que es supererogatorio en el ámbito del mercado. En consecuencia, el conflicto de los principios de justicia en el ámbito constitucional - que apunta a la equidad material, a la solidaridad social y a la justicia distributiva - con los principios de justicia en el mercado - fundamentados en el derecho a la propiedad, la seguridad jurídica y la igualdad formal - configura a los segundos como medios inadecuados para garantizar los fines de los primeros.

\section{Conclusiones}

Los deudores de crédito para vivienda y sus relaciones contractuales privadas aparecieron en el panorama constitucional con la crisis hipotecaria de 1999, la cual generó una ruptura en el contenido contractual de los créditos, configurados en un modelo habitacional de mercado con subsidio a la demanda, y en la forma de comprensión de la naturaleza y exigibilidad del derecho a la vivienda, el cual había estado dormido en la Constitución durante su primera década de vigencia.

La Corte Constitucional colombiana, atendiendo a demandas de la ciudadanía respecto de la protección del derecho a la vivienda, ha jugado un rol significativo en el desarrollo del marco normativo en torno a la adquisición de vivienda. Al haberse condicionado el acceso a la vivienda a la celebración de una relación de crédito, la política pública del Estado colombiano generó el espacio de encuentro entre el derecho privado y el derecho constitucional a través de la figura del deudor. Este sujeto, que para el derecho privado está prima 
facie identificado y suscrito a roles, deberes y derechos claros y generales establecidos en los códigos liberales de derecho privado, una vez convertido en un sujeto de protección constitucional, es definido nuevamente, esta vez desde un intento de conciliación entre el derecho constitucional y el privado. Esta nueva delimitación genera, desde la desprotección práctica del deudor, una búsqueda constitucional de la manera más adecuada de conferirle protección.

Ante la urgencia de atender las consecuencias de la crisis hipotecaria, la Corte Constitucional consideró que los deudores merecían protección constitucional, por lo cual estableció reglas contractuales y procesales orientadas a aliviar su situación económica. Tales reglas, influenciadas por la cercanía con la crisis, identificaron a los deudores como víctimas del sistema financiero y terminaron por proteger contractualmente a los propietarios deudores sin examinar si eran titulares del derecho a la vivienda o si, por el contrario, utilizaban los inmuebles para llevar a cabo actividades de especulación. Ahora, paulatinamente, a medida que se alejan las situaciones relacionadas con la crisis, la jurisprudencia constitucional ha reducido la protección generalizada que recibieron los deudores y ha pasado a hacer del "deudor" una categoría débil de la cual no se desprende, necesariamente, una protección especial.

\section{Referencias}

Alan Gilbert, Helping the poor through housing subsidies: lessons from Chile, Colombia and South Africa, 28 Habitat International, n. ${ }^{\circ}$ 1, 13-40 (2004). https://doi.org/10.1016/S0197-3975(02)00070-X

Banco Mundial, Derechos de Crédito y Procesos Concursales (2006).

Christian Courtis (ed.), El juego de los juristas. Ensayo de caracterización de la investigación dogmática. En Observar la ley. Ensayos sobre metodología de la investigación jurídica, 105-153 (Editorial Trotta, 2006).

Código Civil Colombiano [CCC]. Ley 57 de 1887. 15 de abril de 1887 (Colombia).

Consejo de Estado. Sala de lo Contencioso Administrativo. Sección Cuarta. 21 de mayo de 1999. C. P. Daniel Manrique Guzmán. Expediente 9280.

Consejo de Estado. Sala de lo Contencioso Administrativo. Sección Tercera, Subsección C. 8 de julio de 2015. C.P. Jaime Orlando Santofimio.

Consejo Nacional de Política Económica y Social (CONPES), Programa de Vivienda Social, n. 2484 (1990). https:/ /colaboracion.dnp.gov.co/CDT/Conpes/Econ\%C3\%B3micos/2484.pdf

Corte Constitucional de Colombia. Sentencia C-136 de 1999 (M.P. José Gregorio Hernández Galindo; 4 de marzo de 1999).

Corte Constitucional de Colombia. Sentencia C-252 de 1998 (M.P. Carmenza Isaza de Gómez; 26 de mayo de 1998).

Corte Constitucional de Colombia. Sentencia C-383 de 1999 (M.P. Alfredo Beltrán Sierra; 27 de mayo de 1999).

Corte Constitucional de Colombia. Sentencia C-700 de 1999 (M.P. José Gregorio Hernández Galindo; 16 de septiembre de 1999).

Corte Constitucional de Colombia. Sentencia C-747 de 1999. (M.P. Alfredo Beltrán Sierra; 6 de octubre de 1999).

Corte Constitucional de Colombia. Sentencia C-936 de 2003 (M.P. Eduardo Montealegre Lynett; 15 de octubre de 2003).

Corte Constitucional de Colombia. Sentencia C-955 de 2000 (M. P. José Gregorio Hernández Galindo; 26 de julio de 2000).

David Kennedy, The "Rule of Law," Political Choices and Development Common Sense, en Political Choices, and Development Common Sense, 95-173 (D. M. Trubek \& A. Santos eds., Cambridge University Press, 2006).

Decreto 663 de 1993. Por medio del cual se actualiza el Estatuto Orgánico del Sistema Financiero y se modifica su titulación y numeración. 2 de abril de 1993. D.O. No. 40820.

Departamento Nacional de Planeación (DNP), Plan Nacional de Desarrollo Las Cuatro Estrategias (1972). https://c olaboracion.dnp.gov.co/CDT/PND/Pastrana1_Prologo.pdf 
Departamento Nacional de Planeación (DNP), Plan Nacional de Desarrollo La Revolución Pacífica (1991). https:// colaboracion.dnp.gov.co/CDT/PND/Gaviria_Prologo.pdf

Departamento Nacional de Planeación (DNP), Plan Nacional de Desarrollo Pacto por la Equidad (2019). https://w ww.dnp.gov.co/DNPN/Paginas/Plan-Nacional-de-Desarrollo.aspx

Doris Tarchópulos Sierra, El sistema nacional de vivienda de interés social (1990-2007), en Vivienda Social en Colombia. Una mirada desde su legislación 1918-2005 (Olga Lucía Ceballos ed., 2008).

Francisco Barreto Valderrama, La crisis del sistema UPAC como crisis social y su dimensión jurídica: politica, regulación y neoconstitucionalismo, en Los actores en la crisis económica de fin de siglo, 101-162 (Miguel Urrutia \& Jorge Llano eds., Universidad de Los Andes, 2012).

Günter Held, Políticas de viviendas de interés social orientadas al mercado: experiencias recientes con subsidios a la demanda en Chile, Costa Rica y Colombia (CEPAL, 2000). https://repositorio.cepal.org/bitstream/handle/1 1362/5304/1/S00050485_es.pdf

Iris Marion Young, Two concepts of self-determination, en Ethnicity, Nationalism, and Minority Rights, 176-196 (Stephen May, Tariq Modood, \& Judith Squires eds., 2004). https://doi.org/10.1017/CBO9780511489235.0 09

John Rawls, Teoría de la justicia (Fondo de Cultura Económica, 2006 [1971]).

Jorge Llano \& Miguel Urrutia, Los actores en la crisis económica de fin de siglo (Ediciones Uniandes, 2012).

Lauchlin Bernard Currie, Operación Colombia (Cámara de Comercio de Barraquilla, 1965).

Laudo del 12 de noviembre de 2014, Tribunal del Centro de Arbitraje y Conciliación de la Cámara de Comercio de Bogotá integrado por los árbitros José Armando Bonivento Jiménez, Jorge Pinzón Sánchez y José Vicente Guzmán Escobar.

Ley 31 de 1992. Por la cual se dictan las normas a las que deberá sujetarse el Banco de la República para el ejercicio de sus funciones, el Gobierno para señalar el régimen de cambio internacional, para la expedición de los Estatutos del Banco y para el ejercicio de las funciones de inspección, vigilancia y control del mismo, se determinan las entidades a las cuales pasarán los Fondos de Fomento que administra el Banco y se dictan otras disposiciones. 21 de diciembre de 1992. D.O. No. 40707.

Ley 546 de 1999. Por la cual se dictan normas en materia de vivienda, se señalan los objetivos y criterios generales a los cuales debe sujetarse el Gobierno Nacional para regular un sistema especializado para su financiación, se crean instrumentos de ahorro destinado a dicha financiación, se dictan medidas relacionadas con los impuestos y otros costos vinculados a la construcción y negociación de vivienda. 23 de diciembre de 1999. D.O. No. 43827.

Ley 795 de 2003. Por la cual se ajustan algunas normas del Estatuto Orgánico del Sistema Financiero y se dictan otras disposiciones. 14 de enero de 2003. D.O. No. 45064.

Mariana Bernal Fandiño, El deber de coherencia en los contratos y la regla del Venire contra Factum Proprium, 6 International Law: Revista Colombiana de Derecho Internacional, n. ${ }^{\circ} 13,291-321$, (2008). https://revistas.jav eriana.edu.co/index.php/internationallaw/article/view/13909

Mariana Bernal Fandiño, El solidarismo contractual - especial referencia al derecho francés-, 56 Vniversitas, n. ${ }^{\circ} 114$, 15-30 (2007). https://revistas.javeriana.edu.co/index.php/vnijuri/article/view/14588

Michael Walzer, Politics and passion: Toward a more egalitarian liberalism (Yale University Press, 2004). https://ww w.jstor.org/stable/j.cttlnpmwc

Miguel Urrutia \& Olga Namén, Historia del crédito hipotecario en Colombia, 30 Revista Ensayos sobre política económica, n. ${ }^{\circ}$ 67, 282-306 (2012). https://repositorio.banrep.gov.co/bitstream/handle/20.500.12134/6455/ espe.pdf

Ministerio de Vivienda, Ciudad y Territorio, Colombia: 100 años de políticas habitacionales (2014). http://www.mi nvivienda.gov.co/Documents/100anosdepoliticashabitacionales.pdf

Philip Pettit, Republicanism: A theory of freedom and government (Oxford University Press, 1997). 
Sergio Clavijo, Alejandro Vera \& Ekaterina Cuéllar, Crisis económicas e implicaciones de política (1995-2016), Carta Financiera, n. ${ }^{\circ} 174$ (2016). https://orenatocaunp.files.wordpress.com/2018/03/expo-11-la-crisis-econc3b3mic as-e-implicaciones-de-polc3adtica-1995-201646-6.pdf

Sergio Clavijo, Michel Janna \& Santiago Muñoz, La vivienda en Colombia: sus determinantes socioeconómicos y financieros, Revista Desarrollo y Sociedad, n. ${ }^{\circ} 55,11-165$ (2005). https://doi.org/10.13043/dys.55.3

Yira López-Castro, Viviendo bajo un contrato: la constitucionalización del derecho contractual, 13 Revista Jurídicas, n. ${ }^{\circ}$ 1, 82-99 (2016). https://doi.org/10.17151/jurid.2016.13.1.6

Yves Dezalay \& Brian Garth, La internacionalización de las luchas por el poder (ILSA, 2002).

\section{Notas}

* Artículo de investigación resultado del proyecto "ética, mercado y derechos" que desarrollan los grupos de investigación "Ética Aplicada, Trabajo y Cambio Social” y “Derecho Privado” de la Universidad del Rosario.

1 Este estudio identificó las sentencias emitidas por la Corte Constitucional en el periodo 1991- 2016 en las que se resolvieron asuntos relacionados con créditos hipotecarios, leasing habitacional y seguros de vida de deudores. Posteriormente, tales sentencias fueron categorizadas con el objetivo de identificar los criterios utilizados en la argumentación de la Corte Constitucional al momento de determinar si el deudor debía ser protegido.

2 Christian Courtis (ed.), El juego de los juristas. Ensayo de caracterización de la investigación dogmática. En Observar la ley. Ensayos sobre metodología de la investigación jurídica, 149 (Editorial Trotta, 2006).

3 John Rawls, Teoría de la justicia (Fondo de Cultura Económica, 2006 [1971]).

4 El Banco Central Hipotecario (BCH), creado en 1932, y el Instituto de Crédito Territorial (ICT), creado en 1939, eran entidades estatales que construían viviendas para venderlas y prestaban servicios de crédito con recursos del presupuesto nacional. El BCH "construía urbanizaciones que posteriormente vendía a personas naturales. Los beneficiados estaban en el 50\% más acaudalado de la población urbana” Miguel Urrutia \& Olga Namén, Historia del crédito hipotecario en Colombia, 30 Revista Ensayos sobre política económica, n. ${ }^{\circ}$ 67, 285 (2012). Por otra parte, el ICT diseñaba programas de vivienda y proyectos, actuaba como urbanista, constructor de vivienda y financiador viviendas para campesinos y empleados pobres. Günter Held, Políticas de viviendas de interés social orientadas al mercado: experiencias recientes con subsidios a la demanda en Chile, Costa Rica y Colombia (CEPAL, 2000), concediendo "créditos de largo plazo a los compradores con tasas de interés negativas en términos reales” Departamento Nacional de Planeación (DNP), Plan Nacional de Desarrollo La Revolución Pacífica, 26 (1991).

5 Una de las primeras relaciones contractuales intervenidas por el Estado fue la de arrendamiento. La Ley $7^{\circ}$ de 1943 autorizó al gobierno para dictar "las medidas necesarias, a fin de establecer el control de los arrendamientos" (artículo 3). Con base en tal autorización se expidieron una serie de decretos que prohibieron a los arrendadores exigir a los arrendatarios realizar depósitos en dinero u otorgar cauciones reales (Decreto 453 de 1956); congelaron los precios de los arrendamientos (Decreto 1070 de 1956), establecieron políticas de control de precios de los cánones para evitar la especulación (Decretos 1849 de 1956 y 344 de 1965).

6 Por ejemplo, se expidió la Ley 85 de 1946, la cual ordenó que el interés en los préstamos del ICT fuera "en todo caso del dos por ciento (2\%) anual”, el plazo de amortización de hasta de 30 años, con la obligación de pactar un seguro de vida "que permita saldar la deuda del campesino en el momento en que éste muera". En 1958 se crearon diversas modalidades de crédito, que se concedían a los deudores hasta seis años de plazo para comenzar a pagar las cuotas de amortización y en las que se establecía la posibilidad de aceptar como garantía una segunda hipoteca (Decreto 499 de 1958). Se expidieron normas para "fomentar la construcción de viviendas urbanas, como solución al problema de los arrendamientos" (Ley 29 de 1945); regular "la financiación de viviendas para los trabajadores” (Ley 85 de 1946); regular "los planes de financiación de vivienda para trabajadores, con pignoración de salarios, cesantías y seguros de vida" (Decreto 1575 de 1946); “fomentar la construcción de viviendas económicas" (Decreto 1132 de 1953); crear "el subsidio familiar de vivienda" (Decreto 2462 de 1954 y 499 de 1958).

7 Departamento Nacional de Planeación (DNP), Plan Nacional de Desarrollo Las Cuatro Estrategias, 4 (1972).

8 Lauchlin Bernard Currie, Operación Colombia, 50 (Cámara de Comercio de Barraquilla, 1965).

9 Doris Tarchópulos Sierra, El sistema nacional de vivienda de interés social (1990-2007), en Vivienda Social en Colombia. Una mirada desde su legislación 1918-2005, 181 (Olga Lucía Ceballos ed., 2008).

10 Así, en primer lugar, la política económica de liberalización de servicios financieros se materializó en las leyes 45 de 1990 , 9 de 1991 y 35 de 1993. En relación con el ahorro obligatorio destinado a la adquisición de vivienda de los trabajadores, se expidió la Ley 50 de 1990 para regular las cesantías como una prestación a cargo de los empleadores, administrada por sociedades financieras especializadas. En materia de subsidios, se expidió la Ley $3^{\text {a }}$ de 1991, la cual definió a las Viviendas 
de Interés Social (VIS) por su precio de adquisición y al Subsidio Familiar de Vivienda (SFV) como un aporte estatal en dinero o en especie, para obtener la propiedad de una vivienda o mejorarla Consejo Nacional de Política Económica y Social (CONPES), Programa de Vivienda Social, n. ${ }^{\circ} 484$ (1990).

11 Así, para la población de menores recursos la política se centró en los subsidios familiares para la adquisición de vivienda (i); para los hogares de estrato medio se creó el mecanismo de protección contra la inflación (ii); para los hogares con mayores ingresos se mantuvieron los beneficios tributarios para incentivar el ahorro para compra de vivienda mediante las Cuentas de Ahorro para el Fomento de la Construcción (AFC) (iii) y, para diferentes segmentos se han creado periódicamente subsidios a la tasa de interés (iv).

12 La Ley 1537 de 2012 creó el Programa de Viviendas Gratis. En la estructura negocial de este programa, los actores protagónicos son las fiduciarias, los bancos y los constructores, cuyas relaciones contractuales se regulan por el derecho privado.

13 Chile fue el precursor del modelo de subsidio del 100\% implementado en 1977, el cual es, según Gilbert extraño en el mundo: "Hoy en día, pocos gobiernos están dispuestos a ofrecer subsidios a la vivienda para los pobres a menos que se entreguen como subsidios directos de capital" [Traducción libre] Alan Gilbert, Helping the poor through housing subsidies: lessons from Chile, Colombia and South Africa, 28 Habitat International, n. ${ }^{\circ} 1,13$ (2004).

14 En el Plan Nacional de Desarrollo Pacto por Colombia, Pacto por la Equidad (2018-2022), la política habitacional se explica bajo el título "Vivienda y entornos dignos e incluyentes". Departamento Nacional de Planeación (DNP), Plan Nacional de Desarrollo Pacto por la Equidad (2019).

15 Este cambio en las perspectivas sobre el desarrollo y la conformación de los marcos jurídicos respecto de la economía hasta comienzos del siglo veintiuno pueden verse, por ejemplo, en Yves Dezalay \& Brian Garth, La internacionalización de las luchas por el poder, capítulos 12-14 (ILSA, 2002) y David Kennedy, The "Rule of Law," Political Choices and Development Common Sense, en Political Choices, and Development Common Sense, 95-173 (D. M. Trubek \& A. Santos eds., Cambridge University Press, 2006).

16 Estos cambios se materializan en las Resoluciones 26 de 1994 y 18 de 1995 en las que se señala que el valor en moneda legal de la UPAC será "equivalente al $74 \%$ del promedio móvil de la DTF efectiva".

17 Llano y Urrutia señalan que entre 1990 y 1997 el crédito hipotecario para vivienda creció 165\% Jorge Llano \& Miguel Urrutia, Los actores en la crisis económica de fin de siglo,146 (Ediciones Uniandes, 2012). Así, mientras en 1991 la relación cartera/PIB era del 20\%, en 1997 había llegado al 34\%. Sergio Clavijo, Alejandro Vera \& Ekaterina Cuéllar, Crisis económicas e implicaciones de política (1995-2016), Carta Financiera, n. 174, 10 (2016).

18 Barreto explica como la Junta Directiva del Banco de la República adoptó "una política de contracción monetaria, induciendo un alza en las tasas de interés del mercado. En consecuencia, las tasas reales de colocación del sistema financiero pasaron, en promedio, del 9\% entre 1992 y 1993 al 17\% entre 1994 y 1996 (...). A finales de 1998 la tasa real de colocación alcanzó niveles del 25\%" (cursiva en el texto original). Francisco Barreto Valderrama, La crisis del sistema UPAC como crisis social y su dimensión jurídica: política, regulación y neoconstitucionalismo, en Los actores en la crisis económica de fin de siglo, 116-117 (Miguel Urrutia \& Jorge Llano eds., Universidad de Los Andes, 2012).

19 Llano y Urrutia explican que "la burbuja" de los precios de vivienda coincidió con la crisis económica y financiera internacional que había comenzado en Asia y Rusia y que conllevó para Colombia una reducción del flujo de capitales que hicieron aumentar las tasas de interés colombianas "al reducirse la liquidez en la economía y aumentar el riesgo del pás" y que los créditos hipotecarios vencidos pasaron "del 5.6\% en diciembre de 1996 a 11.9\% en 1998" Jorge Llano \& Miguel Urrutia, op. cit., 51-53.

20 Sobre la disminución de los precios de los inmuebles se explica que "ocurrió una desvalorización de la vivienda que hemos estimado en cerca de 37\% a nivel de las principales ciudades y de 39\% en el caso de Bogotá durante el periodo 1995-2002, la cual recoge todo el ciclo de auge-colapso hipotecario. Como resultado de dicha desvalorización, veremos que el valor de una vivienda de $100 \mathrm{mts} .2$, ubicada en un barrio de estrato relativamente alto, era tan solo de US\$72,000 en Bogotá o unos US\$50,000 en las principales ciudades hacia finales del año 2002”. Sergio Clavijo, Michel Janna \& Santiago Muñoz, La vivienda en Colombia: sus determinantes socioeconómicos y financieros, Revista Desarrollo y Sociedad, n. ${ }^{\circ}$ 55, 11-165 (2005).

21 El 16 de diciembre de 1998, el gobierno expidió los decretos 2330 y 2331 de 1998. Mediante el primero de ellos, declaraba el estado de emergencia y con el segundo establecía las medidas adoptadas por el gobierno para "resolver la situación de los sectores financiero y cooperativo, aliviar la situación de los deudores por créditos de vivienda y de los ahorradores de las entidades cooperativas en liquidación".

22 Corte Constitucional, sentencia C-122 de 1999.

23 Corte Constitucional de Colombia. Sentencia C-136 de 1999 (M.P. José Gregorio Hernández Galindo; 4 de marzo de 1999).

24 Íd.

25 Se trataba de una demanda en contra del art. $1^{\circ}$, el cual señalaba: "El Banco de la República calculará mensualmente para cada uno de los días del mes siguiente e informará con idéntica periodicidad a las corporaciones de ahorro y vivienda, el 
valor en moneda legal de la Unidad de Poder Adquisitivo Constante (UPAC), equivalente al setenta y cuatro por ciento (74\%) del promedio móvil de la tasa DTF efectiva de que tratan las Resoluciones 42 de 1988 de la Junta Monetaria y Externa \# 17 de 1993 de la Junta Directiva de las cuatro (4) semanas anteriores a la fecha de cálculo".

26 Ley 31 de 1992. Por la cual se dictan las normas a las que deberá sujetarse el Banco de la República para el ejercicio de sus funciones, el Gobierno para señalar el régimen de cambio internacional, para la expedición de los Estatutos del Banco y para el ejercicio de las funciones de inspección, vigilancia y control del mismo, se determinan las entidades a las cuales pasarán los Fondos de Fomento que administra el Banco y se dictan otras disposiciones. 21 de diciembre de 1992. D.O. No. 40707. Literal f del artículo 16.

27 Consejo de Estado. Sala de lo Contencioso Administrativo. Sección Cuarta. 21 de mayo de 1999. C. P. Daniel Manrique Guzmán. Expediente 9280.

28 Artículos 18, 19, 20, 21, 22, 23, 134, 135, 136, 137, 138, 139 y 140 del Decreto 663 de 1993. Por medio del cual se actualiza el Estatuto Orgánico del Sistema Financiero y se modifica su titulación y numeración. 2 de abril de 1993. D.O. No. 40820.

29 Corte Constitucional de Colombia. Sentencia C-955 de 2000 (M. P. José Gregorio Hernández Galindo; 26 de julio de 2000).

$30 \quad$ Ley 31 de 1992 . Artículo 16

31 El Laudo es de fecha 12 de noviembre de 2014. El Tribunal estuvo integrado por los árbitros José Armando Bonivento Jiménez, Jorge Pinzón Sánchez y José Vicente Guzmán Escobar. Este último salvó parcialmente el voto indicando que: "mi conclusión es que la voluntad de las partes de este contrato de seguro, esto es, el Banco de la República como asegurado, y Seguros Generales Suramericana S.A. y Allianz Seguros S.A. como aseguradoras, era que la responsabilidad derivada del ejercicio de las funciones del Banco, a través de su Junta Directiva, como autoridad monetaria, crediticia y cambiaria, estuvieran amparadas en la cobertura de responsabilidad civil contenida en dicho anexo de la Póliza de Seguro Global bancario \#1999”.

32 Consejo de Estado. Sección Tercera, Subsección C. 8 de julio de 2015. C.P. Jaime Orlando Santofimio.

33 Salvaron el voto los magistrados Luis Guillermo Guerrero Pérez y Alejandro Linares Cantillo. Adicionalmente, las aseguradoras Seguros Generales Suramericana S.A y Allianz Seguros S.A. solicitaron la nulidad de la sentencia SU-556 de 2016. La Sala Plena negó la solicitud de nulidad mediante auto 037 de 2017, en el que salvaron el voto nuevamente los mismos magistrados.

34 Corte Constitucional de Colombia. Sentencia C-252 de 1998 (M.P. Carmenza Isaza de Gómez; 26 de mayo de 1998).

35 La sentencia derogó los artículos 18, 19, 20, 21, 22, 23, 134, 135, 136, 137, 138, 139 y 140 del Decreto 663 de 1993. Por medio del cual se actualiza el Estatuto Orgánico del Sistema Financiero y se modifica su titulación y numeración. 2 de abril de 1993. D.O. No. 40820.

36 Corte Constitucional de Colombia. Sentencia C-700 de 1999 (M.P. José Gregorio Hernández Galindo; 16 de septiembre de 1999).

37 Las reglas que examinó la Corte fueron los numerales 1 y 3 del Artículo 121 del Estatuto Orgánico del Sistema Financiero que señalan: "1. Capitalización de intereses en operaciones de largo plazo. En operaciones de largo plazo los establecimientos de crédito podrán utilizar sistemas de pago que contemplen la capitalización de intereses, de conformidad con las reglamentaciones que para el efecto expida el Gobierno Nacional (...) 3. Límites a los intereses. De conformidad con el artículo 64 de la ley 45 de 1990 y para los efectos del artículo 884 del Código de Comercio, en las obligaciones pactadas en unidades de poder adquisitivo constante (UPAC) o respecto de las cuales se estipule cualquier otra cláusula de reajuste, la corrección monetaria o el correspondiente reajuste computará como interés".

38 La inconstitucionalidad quedó expresada en estos términos: declárase "la inexequibilidad del numeral tercero del artículo 121 del Decreto Ley 0663 de 1993, así como la de la expresión ‘que contemplen la capitalización de intereses’ contenida en el numeral primero de la norma en mención, únicamente en cuanto a los créditos para la financiación de vivienda a largo plazo, inexequibilidad cuyos efectos se difieren hasta el 20 de junio del año 2000, como fecha límite para que el Congreso expida la ley marco correspondiente" (Corte Constitucional, C-747 de 1999).

39 El derecho a la vivienda ha sido un derecho cuya justiciabilidad ha sido muy problemática en la jurisprudencia de la Corte Constitucional. La línea argumentativa que la Corte adoptó durante los primeros años de vigencia de la Constitución negaba la exigibilidad del derecho a la vivienda mediante la acción de tutela al considerar que se trata de una "carga" que envuelve un "compromiso programático". Las decisiones que hacen parte de esta línea son: T-423 de 1992, T-308 de 1993, T-382 de 1993, T-021 de 1995, T-251 de 1995, T-495 de 1995, T-499 de 1995, T-258 de 1997, T-203 de 1999. Otra línea jurisprudencial ha considerado que el derecho a la vivienda puede ser exigible mediante la acción de tutela si su afectación vulnera o pone en peligro un derecho cuyo carácter fundamental no ofrezca dudas (T-617 de 1995, T-011 de 1998, T-1165 de 2001, T-756 de 2003, T-363 de 2004, T-1091 de 2005, T-079 de 2008).

40 La Ley 546 otorgó un plazo de tres meses para la modificación de los documentos en los que consten las obligaciones para redenominar las obligaciones en UVR (Unidad de Valor Real) y reliquidar los créditos incluyendo los abonos. 
Transcurrido ese periodo sin que se hubiere logrado la modificación tales obligaciones "se entenderán expresadas en UVR, por ministerio de la presente ley" (artículo 38).

41 La línea jurisprudencial sobre estos casos está conformada por más de una veintena de sentencias que de manera estable ha girado sobre el principio de respeto al acto propio en relación con la expedición de paz y salvos, comunicaciones o extractos bancarios realizados por las entidades financieras. En estas sentencias, el respeto al acto propio se analiza como elemento esencial del derecho al debido proceso contractual y al derecho a la vivienda de los deudores. Las sentencias que conforman este precedente son al menos las siguientes: T-672 de 2010, T-129 de 2005, T-006 de 2005, T-733 de 2004, T-727 de 2003, T-608 de 2004, T-079 de 2004, T-083 de 2003, T-1085 de 2002, T-141, T-323 y T-346 de 2003, T-544 y T-546 de 2003, T-550 y T-705 de 2003, T-959 de 2003, T-1085 de 2002.

42 La línea jurisprudencial sobre modificaciones de los créditos de vivienda está conformada por al menos las siguientes sentencias: T-346 de 2015, T-328 de 2014, T-768 de 2012, T-754 de 2011, T-1250 de 2011, T-865 de 2010, T-620 de 2010, T-805 de 2010, T-672 de 2010, T-865 de 2010, T-186 de 2007, T-899 de 2006, T-419 de 2006, T-269 de 2006, T-391 de 2006, T-419 de 2006, T-207 de 2006, T-1063 de 2006, T-1157 de 2005, T-1092 de 2005, T-1186 de 2005, T-993 de 2005, T-652 de 2005, T-626 de 2005, T-611 de 2005, T-129 de 2005, T-006 de 2005,T-212 de 2004, T-608 de 2004, T-375 de 2004, T-793 de 2004, T-822 de 2003, T-423 de 2003, T-346 de 2003, T-323 de 2003, T-141 de 2003, T-1085 de 2002.

43 La jurisprudencia ha aplicado en estos casos la figura del respeto al acto propio. Un completo análisis de este principio en los casos citados puede ser consultado en: Mariana Bernal Fandiño, El deber de coherencia en los contratos y la regla del Venire contra Factum Proprium, 6 International Law: Revista Colombiana de Derecho Internacional, n. ${ }^{\circ} 13,291-321$, (2008).

44 El porcentaje de hogares con vivienda propia que para 1993 era de 63.5\% pasó a ser del 54\% en el 2005 y del $49.9 \%$ en el 2007, con lo cual el número de familias arrendatarias aumentó al pasar del 27\% en 1993 al 31\% en el 2005 y al 33.4\% en el 2007. Ministerio de Vivienda, Ciudad y Territorio, Colombia: 100 años de políticas habitacionales, 89 (2014).

45 El Informe sobre Derechos de Crédito y Procesos Concursales del Banco Mundial incluyó como un riesgo en Colombia la posibilidad de que los créditos de vivienda puedan ser intervenidos por el legislador y por los jueces: "A raíz de la crisis de 1998 hubo interferencia legislativa y jurisprudencial revisando los contratos de préstamos bancarios con hipotecas sobre viviendas y, por ende, esas interferencias podrían sentar un precedente para una intervención futura en la legislación en materia de contratos" Banco Mundial, Derechos de Crédito y Procesos Concursales, 5 (2006).

46 Art. $1^{\circ}$ de la Ley 795 de 2003.

47 El demandante explicaba que "en la práctica": a) el leasing habitacional "es el mismo leasing inmobiliario y, por lo mismo, se sujeta a las condiciones económicas propias de esa clase de contratos mercantiles"; b) En el leasing, "la cuota periódica se fija de acuerdo al interés pactado por las partes, lo cual no necesariamente refleja el interés más bajo del mercado"; c) En el leasing la cuota periódica siempre se establece "con base en el interés compuesto, porque la técnica económica, contable, administrativa y financiera así lo requiere". Esas características violan el "derecho a la vivienda digna" pues "la utilización del sistema de interés compuesto no promueve la vivienda digna a que tienen derecho los colombianos porque los costos y las cuotas periódicas se vuelven inalcanzables".

48 Corte Constitucional de Colombia. Sentencia C-936 de 2003 (M.P. Eduardo Montealegre Lynett; 15 de octubre de 2003).

49 Algunas de las sentencias encontradas en la investigación, en las que los accionados son entidades financieras y en las que se alegan acciones $\mathrm{u}$ omisiones en relación con contratos que permiten el acceso a una vivienda son: T-140 de 2015, T-822 de 2003, T-222 de 2004, T-608 de 2004, T-793 del 2004, T-129 de 2005, T-170 de 2005, T-212 de 2005, T-494 de 2005, T-611 de 2005, T-626 de 2005, T-652 de 2005, T-1091 de 2005, T-1092 de 2005, T-1186 de 2005, T-391 de 2006, T-419 de 2006, T-450 de 2006, T-207 de 2006, T-597 de 2006, T-899 de 2006, T-905 de 2007, T-028 de 2008, T-1027 del 2008, T-672 de 2010, T-832 de 2019, T-055 de 2011, T-185 de 2012, T-768 de 2012, T-136 del 2013, T-662 de 2013, T-902 de 2013, T-222 de 2014, T-328 de 2014, T-408 de 2015, T-763 de 2015, T-239 de 2016, T-420 de 2016 y T-035 de 2017.

50 Hacen parte de esta línea las sentencias: SU-157 de 1999, T-661 de 2001; T-083 de 2003; T-179 de 2004; T-321 de 2004, T-263 de 2005; T-676 de 2005, T-847 de 2010 y T-346 de 2015.

51 Sobre el estado de debilidad manifiesta la Corte ha explicado que "no existe definición ni circunstancia única que permita delimitar el contenido de este concepto" (T-277 de 1999).

52 Un análisis sobre el uso de la solidaridad para establecer obligaciones en relaciones entre particulares es realizado en: Mariana Bernal Fandiño, El solidarismo contractual —especial referencia al derecho francés—, 56 Vniversitas, n. ${ }^{\circ} 114$, 15-30 (2007).

53 La solidaridad puede entenderse como "un deber, impuesto a toda persona por el sólo hecho de su pertenencia al conglomerado social, consistente en la vinculación del propio esfuerzo y actividad en beneficio o apoyo de otros asociados o en interés colectivo" (T-037 de 2017). Esta definición aparece mencionada, entre otras, en las sentencias T-073 de 
1998, C-1054 de 2004, T-170 de 2005, C-188 de 2006, C-314 de 2009, C-529 de 2010, T-342 de 2014, C-767 de 2014 y C-177 de 2016.

54 Sobre el uso de la solidaridad como fundamento para intervenir los contratos de vivienda se ha indicado en otro lugar: "Con base en la solidaridad, la Corte en diversas sentencias ha interpretado las relaciones contractuales de vivienda para proteger a los consumidores cuando estos se encuentran en estado de indefensión por ser desplazados (T-212 de 2005 , T-239 de 2013, T-246 de 2014), madres cabeza de familia (T-185 de 2012), portadores de VIH (T-170-05, T-905-07, T-1161 de 2001), sufrir graves afecciones de salud (T-1091 de 2005, T-490 del 2009, T-832 de 2010, T-086 de 2012), ser víctimas de desastres naturales (T-544 de 2009, T-530 de 2011) o ser personas de la tercera edad (T-136 de 2013)” Yira López-Castro, Viviendo bajo un contrato: la constitucionalización del derecho contractual, 13 Revista Jurídicas, n. ${ }^{\circ}$ 1, 91 (2016).

55 Entendemos acá "dominación" como la condición de estar sujeto a la posibilidad del ejercicio arbitrario del poder de un tercero. Esta definición se sigue del sentido dado al término por autores como Philip Pettit, Republicanism: A theory of freedom and government, capítulos 2-3 (Oxford University Press, 1997); Iris Marion Young, Two concepts of selfdetermination, en Ethnicity, Nationalism, and Minority Rights, 176-196 (Stephen May, Tariq Modood, \& Judith Squires eds., 2004) o Michael Walzer, Politics and passion: Toward a more egalitarian liberalism (Yale University Press, 2004).

\section{Licencia Creative Commons CC BY 4.0}

Para citar este articulo/To cite this article: Yira López-Castro \& David Hernández-Zambrano, El endeudamiento para el acceso a la vivienda: los modelos de justicia detrás de la protección constitucional al deudor, 69 Vniversitas (2020). https://doi.org//10.11144/Javeriana.vj69.eavm 